\title{
Família e mulheres no povoamento do antigo Planalto Paulista
}

\author{
Famílias, mulheres e \\ povoamento: São Paulo, século \\ XVII.
}

SAMARA, Eni de Mesquita.

Bauru, Sã o Paulo: EDUSC, 2003. 102 p. (Coleção História).

Eni de Mesquita Samara é professora titular do Departamento de História da Faculdade de Filosofia, Letras e Ciências Humanas da Universidade de São Paulo, atual diretora do Museu Paulista da USP e presidente da ANPUH.

Desde sua tese de doutorado, A família na sociedade paulista do século $X I X,{ }^{1}$ ela tem investigado a família paulista e brasileira em seus diferentes momentos. Nessa public ação volta sua atenção para os primeiros anos da colonização paulista - o século XVII -, a mesma época da obra de José de Alcântara Machado de Oliveira Vida e morte do bandeirante. ${ }^{2}$

o livro de Samara aborda temas consagrados pela Nova História: ${ }^{3}$ a família e as mulheres. A primeira parte da obra trata da família e a segunda, do papel das mulheres no povoa mento paulista. O conteúd o é a presenta do em oito capítulos sintétic os e parágrafos curtos. Contém, a inda, duas gravuras do século XIX, de J ean-Baptiste Debret, uma indic ativa de passeio em família e a outra sobre a vestimenta feminina, assim como quatro gravuras idealizadas a presentando as vestimentas da época, extraídas do trabalho de Belmonte No tempo dos bandeirantes. ${ }^{4}$

Ele se dirige ta nto a o especia lista da História Cultural quanto ao professor de nível médio ou superior do curso de História.

De início, é rea presentada a disc ussão sobre a família colonial brasileira, tendo por baliza o clássico de Gilberto Freyre - Casa-grande \& senzala ${ }^{5}$ - que consagrou o conceito de fa mília extensiva e patriarcal. A seguir, a autora analisa osautores da primeira fase de revisão da temática nos anos 1950 e 1960, culminando, nos anos 1970, com Eni M. Samara, ${ }^{6}$ Iraci del Nero da
Costa, ${ }^{7}$ Elizabeth Kuznesof, ${ }^{8}$ Maria Odila Dias ${ }^{9}$ e outros que indicaram diferentes situações de famílias particularmente no Sul e no Sudeste do país. Nos núcleosurbanos, por exemplo, a família extensa era minoria, enquanto as famílias chefiadas por mulheres representavam um número consid erá vel. Essa revisã o historiog ráfic a não é exaustiva em vista da ausência da tese de Maria Luiza Marcílio, ${ }^{10}$ pioneira na a presentação de dados demográficos da população paulista na passagem do século XVIII para o XIX, que demonstrou coexistir vários tipos de família em São Paulo.

A historiadora destaca ainda que a produção historiográfica ma is recente tem se preocupado em estabelecer paralelos com as organizações familiares de outras regiões. Por exemplo, Alida Metc a If ${ }^{11}$ loc a lizou em Santana de Parnaíba arranjos familiares das regiões de fronteira semelhantes a os a rranjos das áreas de colonização na América do Norte e da América Latina.

A maioria das obras utilizadas na reflexão do modelo de família patriarcal brasileira referese ao século XVIII e, principalmente, a o XIX, haja vista a carência de pesquisas sobre a história brasileira dos primeiros anos.

O capítulo três - "Família, riqueza e poder na São Paulo colonial" - caracteriza a família da elite paulista do Seiscentos. Tanto nas áreas exporta doras qua nto na quelas oc upa das com o abastecimento interno, a terra era privilégio; portanto, estava concentrada em poucasfa mílias que representavam a "nobreza colonial". A posse da terra e de escravos significava prestígio e poder, de forma que as alianças matrimonia is entre a elite garantiam a continuidade desse modelo.

Nos parágrafos seguintes, passa mosa sentir falta das informações sobre as famílias mais humildes. Entretanto, esse subtema é deixado para ser desenvolvido em futuras monografias, pois o trabalho concentra-se na análise historiog ráfica.

Por fim, a autora esclarece ser impossível conceber um padrão de família colonial brasileira, pois oc orreram diferençasa o longo do tempo, a lém das diferenças regionais, de raça e de classe que dificultam a construção de um conceito único de família. 
Disserta, a seguir, sobre as mulheres dos primeiros séculos. A história das mulheres teria se firmado como um desdobramento dos estudos da família. A cara cteriza ção do papel social das mulheres começ ou com as a ná lises das mulheres chefes de grupos familia res. O folc lore e a história oral também descreviam mulheres fortes que eram protetoras do lar na época dos bandeirantes. Acrescida do fato de que a população masculina dessa época vivia em constante movimento, essa situação teria delegado às mulheres viúvas ou de maridos ausentes a direção e o provimento da casa.

Credita à falta das fontes históricas o ineditismo do tema. E contra-argumenta que, já que a família e as mulheres estã o qua se ausentes na documentação dos primeiros séculos da colônia, os testamentos e os inventá rios postmortem podem se transformar em fontes privilegia das para essa inclusão e a nálise.

Por essa razão, Alida Metcalf ${ }^{12}$ e Murie Nazza $r^{13}$ selec iona ram as partilhas dos inventários post-mortem a fim de compreender a participação das mulheres da colônia na vida social. Na partilha constavam as informações sobre os dotese a diantamentos recebidos pelos filhos, assim como a distribuição da terça estipulada no testamento. A análise dessa documentação revelou, para Nazzari, o privilegia mento das filhas a tra vés dos dotese das terças legadas pelos pais de Santana de Pamaíba. Acrescenta, a inda, que Charles Boxer ${ }^{14}$ localizou algumas mulheres mais poderosas do que os homens nas colônias ibéricas.

Eni Sa ma ra ilustra os diversos c a pítulos com casos de mulheres gerencia doras dos seus bens: por exemplo, a rebelde Maria da Anunciação, casa da com Antonio Francisc o Ba ruel, que deixou com o irmão a administra ção dos seus bens; ou as viúvas Lucrécia Leme e Catharina Paes, incumbidas pelos falecidos da total responsabilidade pelo espólio.

E conclui que

[...] essa História não pode ser considerada marginal, um adendo ou mesmo um suplemento à parte, mas sim uma História mais próxima da realidade em que vivemos no passado e que hoje é analisada na sua complexidade de variáveis e especialmente com uma visão inova dora e multid isc iplinar ( $p$. 90).

O livro cumpre seus objetivos, pois nos apresenta, em linguagem clara e concisa, o debate atual sobre o papel da família e das mulheres nos primeiros séculos das capitanias paulista s. As refe rênc ia s b ib liog rá fic a s c o inc idem com as obras necessárias para um curso de graduação ou pós-gra dua ção sobre o tema. Isso porque as abordagens nos diversos capítulos foram "problemátic as instigantese foram tra ta das orig ina Imente como a ula s nos conc ursos de LivreDocência e titulatura que realizei no Departa mento de História" da Universida de de São Paulo (p. 8).

\section{Notas}

1 SAMARA, 1980.

2 OLVEIRA, 1943.

${ }^{3}$ Eni M. Samara ressaltou na sua tese de doutorado que a obra de Philippe Ariès L'Enfant et la vie familiale sous I'Ancien Régime (ARIES, 1973) serviu-lhe de apoio metodológic o e conceitual para aquela pesquisa. Sobre os novos temas trata dos pela Histónia, verJ ac ques LEGOFF e Pierre NORA, 1995. Para as novas abordagens desenvolvidas pela historiografia brasileira, ver Ciro CARDOSO e Ronaldo VAINFAS, 1997.

${ }^{4}$ SAMARA, 1980, p. 66, 67 e 69. As gravuras de DEBRET, 1954, são representações da época em que o artista visitou o Brasil, no início do século XIX, sendo editadas entre 1834 e 1839; por outro lado, as gravuras de BELMONTE, 1939, foram criadas no século XX para ilustra $r$ os livros sobre o passado.

${ }^{5}$ FREYRE, 1933.

${ }^{6}$ SAMARA, 1980

${ }^{7}$ COSTA, 1977

${ }^{8}$ KUZNESOF, 1986.

${ }^{9}$ DIAS, 1982.

10 MARCÍLO, 1974

11 METCALF, 1992.

12 METCALF, 1992.

13 NAZZARI, 1991.

${ }^{14}$ BOXER, 1975.

\section{Referências bibliográficas}

ARIÈS, Philippe. L'Enfant et la vie familiale sous l'Ancien Régime. Paris: Seuil, 1973.

BELMONTE. No tempo dos bandeirantes. São Paulo: Gráfica da Prefeitura, 1939. 310 p.

BOXER, Cha rles R. Mary and Misogyny: Women in Iberian Expansion Overseas, 1415-1815, Some Facts, Fancies, and Personalities. London: Duckworth, 1975. 142 p.

CARDOSO, Ciro Flamarion; VAINFAS, Ro naldo (Orgs.). Domínios da história: ensa ios de teoria e metodologia. Rio de Janeiro: Campus, 1997. $508 \mathrm{p}$.

COSTA, Iraci del Nero da. "A estrutura familiar e domiciliária em Vila Rica no alvorecer do século XIX". Revista do Instituto de Estudos Brasileiros, USP, São Paulo, v. 19, p. 17-34, 1977.

DEBRET, J ean Baptiste (1768-1848). Viagem pitoresca e histórica ao Brasil. Paris: R. de Castro Maya, 1954. 23 p. 100 plates. 
DIAS, Maria Odila da Silva. Anna Gertrudes de Jesus, mulher da terra. 1982. Tese (Livre Docência em História) - Faculdade de Filosofia, Letras e Ciências Humanas da Universidade de São Paulo.

FREYRE, Gilberto. Casa-grande \& senzala: formação da familia brasleira sob o regimen de economia patriarchal. Rio de Janeiro: Maia \& Schmidt, 1933. 517 p.

KUZNESOF, Elizabeth Anne. Household Economy and Urban Development: São Paulo, 1765 to 1836. Boulder: Westview Press, 1986. 216 p.

LE GOFF, J ac ques; NORA, Pierre (Orgs.). História: novos problemas. 4. ed. Tradução: Theo Santiago. Rio de Janeiro: Francisco Alves, 1995. $193 \mathrm{p}$

MARCílO, Maria Luiza. A cidade de São Paulo: povoamento e população, 1750-1850, com base nos registros paroquiais e nos resenceamentos antigos. Tra dução da autora da tese de 1968. São Paulo: Pioneira/EDUSP, 1974. 220 p.
METCALF, Alida. Family and Frontier in Colonial Brazil - Santana de Paranaíba 1580-1822. Berkeley: University of Califomia Press, 1992. $280 \mathrm{p}$.

NAZZARI, Muriel. Disappearance of the Dowry: Women, Families and Social Change in São Paulo, Brazil (1600-1990). Stanford: Stanford University Press, 1991. 245 p.

OLVEIRA, José de Alcântara Machado de. Vida e morte do bandeirante. São Paulo: Martins, 1943. 236 p.

SAMARA, Eni de Mesquita. A família na sociedade paulista do século XIX (1800-1860). 1980. Tese (Doutorado em História) - Faculdade de Filosofia, Letras e Ciências Humanas da Universidade de São Paulo.

Maria Lucília Viveiros Araújo Faculda de de Ec onomia, Administração e Contabilidade da USP 